\title{
Pre- and postlexical loci of contextual effects on word recognition
}

\author{
MARK S. SEIDENBERG, GLORIA S. WATERS, MICHAEL SANDERS, \\ and PEARL LANGER \\ McGill University, Montreal, Quebec, Canada
}

\begin{abstract}
The context in which a word occurs could influence either the actual decoding of the word or a postrecognition judgment of the relatedness of word and context. In this research, we investigated the loci of contextual effects that occur in lexical priming, when prime and target words are related along different dimensions. Both lexical decision and naming tasks were used because previous research had suggested that they are differentially sensitive to postlexical processing. Semantic and associative priming occurred with both tasks. Other facilitative contextual effects, due to syntactic relations between words, backward associations, or changes in the proportion of related items, occurred only with the lexical decision task. The results indicate that only associative and semantic priming facilitate the decoding of a target; the other effects are postlexical. The results are related to the different demands of the naming and lexical decision tasks, and to current models of word recognition.
\end{abstract}

A basic question in psycholinguistic research concerns the manner in which contextual information influences lexical processing. Does contextual information enter into the processes by which a word is recognized, or does it influence processes that occur after recognition is achieved? Some models (e.g., Marslen-Wilson \& Tyler, 1980; Rumelhart, 1977) emphasize that the bottom-up analysis of a word is supplemented by nonlexical (i.e., syntactic, semantic, or pragmatic) information provided by the context, facilitating recognition. An alternate proposal (Forster, 1979; Gough, Alford, \& HolleyWilcox, 1981) is that contextual information does not affect the identification of a word per se; rather, it influences postrecognition comprehension processes involved in the integration of words into meaningful representations (e.g., propositions). According to Forster (1979), skilled word recognition is functionally autonomous because the bottom-up decoding of the input allows recognition to occur without contextual support.

This research was supported by Grants A7924 and A8325 from the Natural Science and Engineering Research Council of Canada and Grant EQ-2074 from the Quebec Ministry of Education (FCAC). Waters was supported by a Social Sciences and Humanities Research Council of Canada postdoctoral fellowship. Experiments 1 and 3 formed parts of undergraduate theses by Sanders and Langer. Gail Fornarolo and Sharon Greene ably assisted in running the experiments. We thank Keith Stanovich and an anonymous reviewer for extensive comments on an carlier draft. Many of the ideas in this paper, especially those concern. ing the lexical decision task, evolved in discussions with Michael Tanenhaus, whom we thank. Much of the research was presented by Seidenberg under the title "Two Kinds of Lexical Priming" at the 1983 meeting of the Psychonomic Society. Reprint requests should be addressed to M. Seidenberg, Department of Psychology, McGill University, 1205 Docteur Penfield, Montreal Quebec, Canada, H3A 1B1.

-Steven W. Keele served as Action Editor for this manuscript.
On this view, the reader's task is to integrate each word with the context, rather than to use the context to facilitate recognition. Stanovich (1980) stressed that autonomous lexical processing is characteristic of skilled reading, with heavy reliance upon context more likely to occur for readers whose bottom-up decoding skills are poor.

Most current models of language comprehension propose that there are interactions among many different types of information. The idea that lexical processing is autonomous represents a hypothesis about the scope of interactive processes. Word recognition may result from interactive processes within the lexicon, but these do not draw upon other types of knowledge. This view is consistent with the proposal that language comprehension results from the operation of modular, domain-specific subsystems, of which the lexicon is one (Fodor, 1983; Seidenberg \& Tanenhaus, in press; Tanenhaus, Carlson, \& Seidenberg, 1984).

The goal of the present research was to identify the loci of contextual effects on lexical processing. Word recognition is a complex process occurring over time; contextual information could influence some aspects of lexical processing but not others. It could influence prelexical processes-that is, the decoding processes that result in identification (recognition) of the signal as a particular word-or postlexical processes, which occur after recognition is completed. Such postlexical processes involve the selection, elaboration, and integration of lexical information for the purpose of comprehending a text or utterance (Cairns, Cowart, \& Jablon, 1981; Seidenberg, Tanenhaus, Leiman, \& Bienkowski, 1982; Tanenhaus et al., 1984). The autonomy hypothesis is a claim about the processes leading to recognition, not postlexical processes. There is clear evidence that post- 
lexical processes are contextually dependent. A study by Merrill, Sperber, and McCauley (1981) provided a striking example. Good and poor readers read sentences such as (1) "The boy petted the cat" and (2) "The boy was scratched by the cat," followed a half second later by target words such as "fur" or "claws," which are related to different characteristics of cats implicated by the contexts. The targets were written in colored ink, and the subjects' task was to name the color (Stroop task). For good readers, targets related to contextually appropriate properties produced more color-naming interference than did unrelated targets. For poor readers, however, targets related to both properties showed interference. The results indicate that recognizing the word "cat" provided access to knowledge about cats; following recognition, good readers retained only the information relevant to the context, whereas poor readers retained both relevant and irrelevant information. Thus, the reader groups were distinguished in terms of their postlexical processing. Note that there is no suggestion from this study that good and poor readers decoded the word "cat" differently, only that their decisions as to which information to retain differed. Analogous results have been obtained in studies of lexical ambiguity resolution (Onifer \& Swinney, 1981; Seidenberg et al., 1982; Simpson, 1981; Swinney, 1979; Tanenhaus, Leiman, \& Seidenberg, 1979).

The fact that postlexical processing is contextually dependent does not violate the autonomy hypothesis because, as the term suggests, it occurs after a word has been recognized. These processes do not reflect changes in the manner in which a word is decoded as a function of context. Thus, in attempting to reconcile the literature on contextual effects with Forster's (1979) proposal, it is necessary to consider whether they are postlexical or not.

A number of studies of contextual effects on word recognition have employed a lexical priming paradigm, in which a single priming word influences the reading of a subsequent, related target word. The associative priming effect obtained with this paradigm (Meyer \& Schvaneveldt, 1971; Meyer, Schvaneveldt, \& Ruddy, 1975; Warren, 1972, 1977) represents a class of contextual effects that are not postlexical. Recognition of a target word (e.g., "nurse") is facilitated if it is preceded by a highly associated priming word (e.g., "doctor"), rather than an unrelated prime (e.g., "chair"). This effect receives a clear interpretation under the Collins and Loftus (1975) spreading activation model. Recognition of the prime results in activation of a node in memory. Activation spreads to the nodes of associated words. Recognition latency is a function of activation level. An associated target has a higher activation level as a result of priming, producing faster recognition. Thus, associative priming affects recognition by increasing the activation level of a target before it is presented. According to Forster (1979), these contextual effects do not violate the autonomy hypothesis because they are wholly a consequence of relations that hold among entries in the mental lexicon, and thus internal to it. Autonomy is violated only when information extrinsic to the lexicon influences lexical processing. This would occur, for example, if syntactic information or the propositional representation of the meaning of an utterance influenced recognition.

Associative priming is a theoretically important phenomenon, because contextual effects that derive from this process do not violate autonomy. However, several results in the literature call into question the spreading activation interpretation of associative priming, and thus the autonomy hypothesis. These studies broaden the scope of lexical priming far beyond simple associative relations between words. A study by Goodman, McClelland, and Gibbs (1981) suggested that priming is not restricted to highly associated pairs, and that it may involve nonlexical knowledge. They obtained facilitation for both associatively related pairs, such as "doctor-nurse," and pairs that were unassociated but formed a syntactic constituent (e.g., "he-sent"). A spreading activation interpretation of this effect leads to absurdity: Activation would have to spread from an entry in memory to all words of a particular grammatical class (e.g., verbs). If the syntactic contexts influenced the decoding of the targets in this experiment, the effect would violate the autonomy hypothesis because it would result from the use of nonlexical information. Lukatela, Kostic, Feldman, and Turvey (1983) and Lukatela, Moraca, Stojnov, Savic, Katz, and Turvey (1983) have reported a similar effect, which they term grammatical priming, in Serbo-Croatian.

Koriat (1981) observed a backward priming effect. The stimuli were word pairs that were asymmetrical in association value. For example, "apple" is a high associate of "fruit," but "fruit" is not a high associate of "apple." Lexical decisions to target words were facili. tated when stimuli were presented both forward ("fruitapple") and backward ("apple-fruit"). This result is alsc difficult to reconcile within a simple spreading activation model, and suggests that priming may be more wide spread than previously thought. Koriat proposed that the backward priming effect was due to spreading activation, whereas the forward effect was due to subjec expectations, a controlled process (Shiffrin \& Schneider 1977). This represented a radical reinterpretation of forward associative priming effects. ${ }^{1}$

Tweedy, Lapinski, and Schvaneveldt (1977) founc that the magnitude of the associative priming effec depended upon the proportion of associated stimuli Facilitation was much greater with a larger proportior of related word pairs, a result replicated by den Heyer Briand, and Dannenbring (1983). This is also difficult tc accommodate with the view that associative primin results from a passive spreading activation process, anc suggests that subjects' expectations or judgments con 
cerning the relatedness of simuli may underlie associative priming.

Finally, Fischler (1977b) observed facilitation both when prime-target pairs were associatively related (e.g. . "doctor-nurse") and when they were semantically related but nonassociated (e.g., "wife-nurse"). Fischler interpreted the result as indicating that the scope of the spreading activation process was much broader than previously thought. However, the associative and semantic effects could also derive from different underlying processes, or from the use of nonlexical information rather than spreading activation.

These effects all resemble simple associative priming in that they reflect the effects of a priming word on a target word, and yet all four present difficulties for a simple spreading activation model. This raises two questions. First, are associative priming and the four other types of contextual effects due to the same or different mechanisms, and second, are these mechanisms consistent with the autonomy hypothesis? Neely (1977) demonstrated that lexical priming can derive from two processes, automatic spreading activation, and a limitedcapacity attentional mechanism (Posner \& Snyder, 1975). The former was observed for associated pairs such as "bird-robin," the latter by manipulating subjects' expectations concerning prime-target relations. These results suggest the possibility that all of the contextual effects in the lexical priming paradigm are due to the attentional mechanism, except for associative priming due to automatic spreading activation. This possibility was mentioned by both Goodman et al. (1981) and Tweedy et al. (1977), whereas Koriat (1981) suggested the exact opposite (i.e., that backward priming is automatic, whereas forward priming derives from expectations).

Assuming that some priming effects result from controlled processes rather than from automatic spreading activation, there is an additional question as to whether or not they violate the autonomy hypothesis. Although Neely's (1977) study clearly isolated associative and attentional mechanisms, it was not clear whether they facilitated target recognition in the same manner. In particular, it was unclear whether the attentional mechanism facilitated the decoding of the target or a postlexical judgment concerning prime-target relatedness. Neely acknowledged both possibilities, stated in somewhat different terms.

The present studies evaluated whether the syntactic semantic, and backward priming effects, and the proportionality effect, derive from postlexical processes and associative priming derives from automatic spreading activation. Testing this hypothesis requires response measures that distinguish between pre- and postlexical contextual effects. This was accomplished by exploiting West and Stanovich's (1982) discovery that the naming and lexical decision tasks are differentially sensitive to postlexical effects. Associative priming is obtained using both tasks (Becker \& Killion, 1977; Meyer et al., 1975; Warren, 1977). However, in Stanovich and West's (1979, 1981. 1983; West \& Stanovich, 1982) extensive studies of sentence-context effects, only lexical decisions were affected by subjects' postlexical judgments as to whether a target word was related to the context.

The lexical decision task appears to reflect not only the difficulty of identifying the target as word or nonword, but also the subject's judgment as to the relationship between the target word and priming context (see also Forster, 1979, and Theios \& Muise, 1977). Lexical decisions in context produce a Stroop-like effect: Although subjects could, in principle, perform the decision based on the results of lexical processing, they seemingly cannot prevent the results of contextual processing from affecting their responses (West \& Stanovich, 1982). Naming a target in context does not tend to produce this Stroop-like interference. Two possible reasons for the task difference have been suggested. One is that naming occurs too rapidly for context to be used (West \& Stanovich, 1982). The other is that contexts could provide information as to whether a word or nonword target is likely; this information might provide additional criteria for making the lexical decision, but cannot facilitate naming a particular target (Forster, 1979). Thus, it is only used in lexical decision.

It follows that if the contextual facilitation due to syntactic, semantic, or backward relations between stimuli, or changes in the proportion of associatively related items, result from the same mechanism as associative priming, the effects should occur with both response measures. Facilitation that is due to subjects' postlexical judgments concerning the relatedness of the stimuli should appear only in lexical decision. The syntactic, semantic, backward, and proportionality effects were all originally obtained in studies using the lexical decision task; the basic goal of the present studies was to determine whether they would occur in naming.

\section{EXPERIMENT 1}

This experiment examined the syntactic priming effect, using both lexical decision and naming tasks. It was a replication of Goodman et al. (1981).

\section{Method}

Subjects. The subjects were 80 (40 in each task) McGill University undergraduates who volunteered or were paid to participate. All were native speakers of English.

Stimuli. The stimuli were taken from the syntactic priming conditions in the Goodman et al. (1981) study. Two lists of stimuli were prepared, following the method used in that study. Each contained 80 trials, including 20 syntactically related pairs ("men-swear," "whose-planet"), 20 unrelated pairs formed by re-pairing the stimuli in the related cases (e.g., "men-planet," "whose-swear"), and 40 word-pseudoword pairs. Each prime word appeared four times in a list, once with a syntactically related target, once with an unrelated target, and twice with two different nonword targets. Each word target appeared with 
both related and unrelated primes. Each list of 80 stimuli contained four counterbalanced blocks, with each prime appearing once in a block and with an equal number of stimuli from each condition in each block. Each subject saw both lists of stimuli, with order of lists counterbalanced between subjects.

Procedure. Presentation of the stimuli and recording of latencies were controlled by an Apple II microcomputer equipped with a real-time clock and video terminal (Amdek Video-300). A hardware modification was performed to eliminate the timing error associated with the $60-\mathrm{Hz}$ scanning rate of the CRT. The real-time clock operated on a millisecond time base. On each trial, a fixation point appeared for $2 \mathrm{sec}$, followed by the prime word for $600 \mathrm{msec}$ a line above where the fixation point had appeared. At the offset of the prime, the target appeared two lines below it until the subject made a response (maximum $=$ $2 \mathrm{sec})$. The subjects were instructed to read the prime word silently and then to respond to the target. In the pronunciation condition, they read the target aloud into a microphone connected to a voice key interfaced to the computer. Mispronunciation errors were recorded by hand. In the lexical decision condition, they pressed external microswitches indicating the word/ nonword decision. This basic methodology was used in all the studies reported in this paper.

\section{Results}

The results are summarized in Table 1 . Latencies in the nonword condition were longer than those in the word conditions and were excluded from further analyses. In the lexical decision task, the related pairs showed $13 \mathrm{msec}$ of facilitation, compared with unrelated pairs, and $1.3 \%$ fewer errors. In naming, the syntactically related pairs showed $5 \mathrm{msec}$ of facilitation, compared with unrelated pairs, but $1.1 \%$ more errors. Statistical analyses were based on subjects' median latencies in each condition and on the square-root transformed number of errors per subject. Separate analyses of variance were computed for the latency and error data, with the factors task (pronunciation and lexical decision) and stimulus type (related, unrelated). In the latency analysis, there were main effects of task $[F(1,78)=13.09$, MSe $=11,540, p<.001]$ and stimulus type $[F(1,78)=$ $11.49, \mathrm{MSe}=270, \mathrm{p}<.002]$. The interaction between the two factors was not significant $[F(1,78)=1.77$, $\mathrm{p}>.15]$. In the error analysis, the effects of task and stimulus type were not significant, but the task $\mathrm{x}$ stimulus type interaction was $[\mathrm{F}(1,78)=7.79$, MSe $=.352$, $\mathrm{p}<.01]$. This differing pattern of results reflects the fact that, whereas the 5-msec priming effect in naming was due to a speed-accuracy tradeoff, the 13 -msec effect

Table 1

Mean Response Latencies (MRL; in Milliseconds) and Percent Errors (PE), Experiment 1

\begin{tabular}{lccccc}
\hline & \multicolumn{4}{c}{ Task } \\
\cline { 2 - 3 } & \multicolumn{3}{c}{ Lexical Decision } & & \multicolumn{2}{c}{ Pronunciation } \\
\cline { 2 - 3 } \cline { 5 - 6 } Condition & MRL & PE & & MRL & PE \\
\hline Syntactic & 564 & 2.1 & & 507 & 2.6 \\
Control & 577 & 3.4 & 512 & 1.5 \\
Difference & +13 & +1.3 & +5 & -1.1 \\
\hline
\end{tabular}

in lexical decision was not. The 13-msec priming effect in lexical decision was significant $[\mathrm{t}(39)=2.73, \mathrm{p}<.01$, two-tailed], as was the $1.3 \%$ difference in errors [ $\mathrm{t}(39)=$ $2.12, \mathrm{p}<.05$, two-tailed]. The 5 -msec facilitation in naming was marginally significant $[\mathrm{t}(39)=1.76, \mathrm{p}<.05$, one-tailed, but $\mathrm{p}>.05$, two-tailed]. There were also significantly more errors on related pairs than on unrelated pairs in naming [ $\mathrm{t}(39)=2.17, \mathrm{p}<.05$, two-tailed] . Thus, syntactically related pairs showed facilitation in lexical decision, as indicated by both latency and error data; in naming, there was a small amount of facilitation, but it produced a concomitant increase in errors on related trials.

\section{Discussion}

The results for the lexical decision task replicate Goodman et al.'s (1981) finding of a small facilitative effect due to syntactic relatedness. The present study yielded differences of $13 \mathrm{msec}$ in latency and 1.3\% in errors, results similar in magnitude to those obtained by Goodman et al. (19 msec and 4\% in their Experiment 1, and $15 \mathrm{msec}$ and $1 \%$ in their Experiment 2, blocked condition). This facilitation did not obtain in the pronunciation task, however. There was a marginally significant 5-msec facilitation effect, but there was also a significant increase in errors on related trials. The asymmetry in the results for the two tasks contrasts with that seen in associative priming, which occurs with both. The results are consistent with the hypothesis that associative priming and syntactic priming result from different processes. The former is due to spreading activation through lexical memory, the latter to subjects' postlexical decision that the stimuli are grammatical.

\section{EXPERIMENT 2}

This experiment examined the effect of the proportion of related stimuli on the magnitude of the associative priming effect. Tweedy et al. (1977) showed that there was greater facilitation with a larger proportion of associative trials. The results were interpreted within Posner and Snyder's (1975) two-factor theory of attention. Associative priming results from the automatic spread of activation in lexical memory; however, subjects' expectations that stimuli will be related introduces an attentional component as well, yielding greater facilitation with a larger proportion of related trials. Whether these mechanisms were thought to influence the same or different aspects of lexical processing was unclear. An alternate interpretation is that there was no automatic priming, and that all of the effects were due to subjects' expectations concerning the stimuli.

If subjects' expectations influence postlexical processes, manipulating the proportion of related trials should affect only lexical decisions. The part of the priming effect due to automatic spreading activation should occur in both tasks. 
Method

Subjects. Forty McGill University undergraduates voluntcered or were paid for their participation.

Stimuli. Twenty pairs of highly associated words were constructed. Twenty pairs of unrelated stimuli were constructed by re-pairing target words with unrelated priming words. The associated and unrelated primes were matched for frequency and length. Each prime appeared once, and each target twice. These stimuli were used in all task and proportion conditions. and are termed the test stimuli.

In the high-proportion lexical decision condition, 20 wordnonword pairs were also included. These consisted of 20 different word primes, and 10 nonword targets that were used twice each. The repetition of targets and nonrepetition of primes followed the pattern for the test stimuli. With 20 related pairs, 20 unrelated pairs, and 20 word-nonword pairs, the proportion of related stimuli was one-third. The proportion of nonwords was also one-third.

In the low-proportion condition, the set of 40 test stimuli was included, as well as 30 word-nonword trials and 30 filler trials of unrelated words. For these 60 trials, each prime was used once, and each target twice. The proportion of related trials was one-fifth. The proportion of nonword trials was $30 \%$, comparable to that in the high-proportion condition.

Stimuli in the pronunciation conditions were identical to those in lexical decision, except that nonword trials were replaced by unrelated word pairs. In the high-proportion condition, there were the 40 pairs of test stimuli ( 20 related, 20 matched unrelated) and 20 unrelated filler pairs. The lowproportion condition consisted of the 40 pairs of test stimuli and 60 unrelated filler pairs. The proportions of related pairs were one-third and one-fifth in the high- and low-proportion conditions, respectively, identical to those in the lexical decision task. The distribution of stimuli in each condition is summarized in Table 2.

This design differed from that used in the den Heyer et al. (1983) and Tweedy et al. (1977) experiments. In those studies, the proportion of related trials was manipulated by including varying numbers of related stimuli. As a consequence, the number of items contributing to the means in the different proportion conditions varied. In the present study, the number of related trials was identical across proportion conditions. When the proportions of related trials are calculated out of the total number of trials, the proportions in the high- and low-proportion conditions in this study (33\% and $20 \%$, respectively) are similar to the proportions in the high- and medium-probability conditions in the den Heyer et al. and Tweedy et al. studies (in both studies, $39 \%$ and $22 \%$, respectively).

Four lists were created by crossing two proportions and two tasks. Each target word appeared once in each half of the list. The halves were counterbalanced so that an equal number of stimuli from each condition appeared in each half. Each sub- ject was assigned randomly to one list; 10 subjects saw each list.

Procedure. Stimuli were presented on an Apple Il microcomputer, as in Experiment 1. Each trial began with the presentation of a fixation point in the center of the video screen. The prime word appeared for $500 \mathrm{msec}$ a line above center; the target appeared a line below center until the subject made a response (maximum $=2 \mathrm{sec}$ ), either manual or vocal. The 60 trials in the high-proportion conditions were presented without interruption; the 100 trials in the low-proportion conditions were divided into two blocks of 50 , and the subjects had a brief rest between blocks.

\section{Results}

Means derived from the subjects' median scores for the related and unrelated stimulus conditions are presented in Table 3.

For the lexical decision task, the magnitude of the priming effect was $41 \mathrm{msec}$ in the low-proportion condition and $76 \mathrm{msec}$ in the high-proportion condition. These results closely replicate Tweedy et al.'s (1977) priming effects of 52 and $78 \mathrm{msec}$, respectively, using a slightly larger proportion of related trials in each condition. In the naming task, however, the effects were $28 \mathrm{msec}$ in the low-proportion condition and $30 \mathrm{msec}$ in the high-proportion condition. Hence, there was associative priming in both tasks, but the proportion of related stimuli influenced only lexical decisions.

An analysis of variance was performed on the subject means, with between-subject factors of task (pronunciation, lexical decision) and proportion of related ttems (high, low) and a within-subject factor of stimulus type (related, unrelated). The main effect of task was significant $[F(1,36)=7.79$, MSe $=10,619, p<.01]$, as was the main effect of stimulus type $[\mathrm{F}(1,36)=72.62$, $\mathrm{MSe}=525, \mathrm{p}<.001]$. The stimulus type $\mathrm{x}$ proportion interaction was marginally significant $[F(1,36)=3.51$, $\mathrm{MSe}=525, .05<\mathrm{p}<.10]$. There was also a significant task $x$ proportion $x$ type interaction $[F(1,36)=8.46$, $\mathrm{MSe}=525, \mathrm{p}<.01]$. The main effect of proportion and the other interactions did not reach significance. The task effect was due to faster latencies in naming than in lexical decision. The main effect of type was due to facilitation for related stimuli compared with unrelated controls. The triple interaction indicates that the propor-

Table 2

Distribution of Stimuli in Experiment 2

Lexical Decision

\begin{tabular}{lll}
\hline \multicolumn{1}{c}{ Lexical Decision } & \multicolumn{1}{c}{ Pronunciation } \\
\hline & High Proportion Stimuli & \\
20 related word pairs & & 20 related word pairs \\
20 matched unrelated word pairs & & 20 matched unrelated word pairs \\
20 word/nonword pairs & & 20 filler unrelated pairs \\
& Low Proportion Stimuli & \\
20 related word pairs & & 20 related word pairs \\
20 matched unrelated word pairs & & 20 matched unrelated word pairs \\
30 filler unrelated pairs & 60 filler unrelated pairs \\
30 word/nonword pairs & \\
\hline
\end{tabular}


Table 3

Mean Response Latencies (MRL; in Milliseconds) and Percent Errors (PE), Experiment 2

\begin{tabular}{llllll}
\hline & \multicolumn{2}{l}{ High Proportion } & & \multicolumn{2}{l}{ Low Proportion } \\
\cline { 2 - 2 } \cline { 5 - 5 } Condition & MRL & PE & & MRL & PE \\
\hline & \multicolumn{2}{l}{ Lexical Decision Task } & & \\
Related & 516 & 1.0 & & 535 & 0.0 \\
Unrelated & 592 & 2.0 & & 576 & 0.0 \\
Difference & +76 & & +41 & \\
& Pronunciation Task & & \\
Related & 482 & & 470 & \\
Unrelated & 512 & & 498 & \\
Difference & +30 & +28 & \\
\hline
\end{tabular}

Note-There were no errors on the pronunciation task.

tion of related items changed the magnitude of the priming effect only in the lexical decision task.

\section{Discussion}

The results are consistent with the view that lexical priming derives from two sources. First, there is an associative priming effect that appears in both tasks. This effect is an automatic consequence of spreading activation. As Fischler (1977a) demonstrated, it occurs even when subjects have no basis on which to expect any stimuli to be related. Second, subjects' expectations concerning the relatedness of stimulus pairs can produce facilitation; these effects result from a veiled control process (Shiffrin \& Schneider, 1977), and, because they are postlexical, they appear in lexical decisions, but not in naming. This interpretation is similar to one originally offered by Tweedy et al. (1977); however, the task differences further indicate that the two sources of contextual facilitation influence different aspects of lexical processing.

\section{EXPERIMENT 3}

This experiment considers the priming effect due to backward association observed by Koriat (1981). Koriat's experiment was based on a study by Warren (1972), who failed to observe the backward effect using the Stroop task. Koriat interpreted the backward priming effect obtained with lexical decision as being due to a kind of reverberatory spreading activation process, in which activation spreads from the target to the associated prime and then back to the target. He also called into question the belief that facilitation resulting from forward association is due to automatic spreading activation, suggesting instead that it is a consequence of controlled processing.

Kiger and Glass (1983) also reported a backward priming effect. They presented pairs of words such as "fruit-apple" in sequence and required subjects to make a lexical decision to the first word. Related pairs showed facilitation, compared with unrelated pairs. They inter- preted the results as indicating that processing of the prime and target can overlap in time.

An altemative hypothesis, however, is that forward priming is due to spreading activation, and that the backward effect is due to a postlexical process. The stimuli could have been processed independently, with subjects recognizing that they are related in a backward direction postlexically. The hypothesis that only lexical decisions are influenced by such postlexical processes would account for the fact that Koriat (1981) obtained the backward effect with this task, whereas Warren (1972) did not obtain it with the Stroop task. This hypothesis was tested in Experiment 3, using Koriat's procedure and the lexical decision and naming tasks. If it is correct, forward priming should occur with both tasks, whereas backward priming should occur only in lexical decision.

Another aspect of Koriat's (1981) study merits attention, however. The stimuli were asymmetrical associates, such as "fruit-apple" and "apple-fruit." Standard association norms indicate that there is a high degree of association in the forward direction, but not in the backward direction. However, the backward stimuli, although low in association value, are nonethe less semantically related. If "associative" priming occurs when stimuli are merely semantically related, but nor highly associated (Fischler, 1977b), the "backward" priming effect observed for "apple-fruit" could actually have been due to a forward effect of semantic related ness.

The way to control for this problem is to use stim. ulus pairs that are highly related in the forward directior and very unrelated in the backward direction. This car be accomplished by using pairs such as "lip-stick" o] "stage-hand," which form common phrases or com pound words in the forward direction but are unrelatec in the backward direction. In Experiment 3, then, thi backward priming effect was evaluated using thest stimuli. Experiment 4 examined the related question $o$ whether priming for semantically related but nonassoci ated pairs results from the same process as associativ priming.

\section{Method}

Subjects. The subjects were 66 McGill University unde graduates who either volunteered or were paid for participation 30 were tested in the lexical decision condition, and 36 in th pronunciation condition.

Stimuli. The stimuli consisted of 20 pairs of words that wer symmetrical associates (e.g., "sheep-wool," "spider-web") an 20 pairs of asymmetrical associates (e.g., "fruit-fly," "bus-boy" see Appendix). Unrelated controls were constructed by re-pairin the stimuli. Each word appeared twice as a prime and twice as target. A sample set of stimuli is presented in Table 4. Eigh conditions resulted from crossing the factors forward versu backward presentation, symmetrical versus asymmetrical, an test versus control. The 20 stimuli presented in the forwar direction, the same stimuli presented in the backward condition and the 40 re-paired control items yielded two sets of 80 pai (symmetrical and asymmetrical).

The items were rated for association value by 100 unde graduates. Four rating lists were prepared, each including on 
Table 4

Sample Stímulus Set, Experiment 3

\begin{tabular}{lll}
\hline & Asymmetrical & Symmetrial \\
\hline \multirow{2}{*}{ forward } & fruit-fly & city-town \\
& bell-hop & bath-tub \\
Backward & ny-fruit & town-city \\
& hop-bell & city-town \\
forward Control & bell-fly & bath-town \\
& fruit-hop & city-tub \\
Backward Control & hop-fruil & tub-city \\
& fly-bell & town-bath
\end{tabular}

fourth of the stimuli, with no repetition of words. The subjects were instructed to rate the extent to which the lirst word in a pair called to mind the second word. The words were written on successive lines to encourage subjects to restrict attention to the forward direction. The ratings indicated that the symmetrical associates were related in both directions, whereas the asymmetrical associates were more related in the forward than in the backward direction. ${ }^{2}$

The stimuli were apportioned into four counterbalanced blocks, with cach pair of words occurring only once in a block and with a quarter of the stimuli from each condition in each block. There were 40 stimuli in each block, 5 of each of the eight types listed in Table 4 . In the lexjcal decision condition, an additional 20 trials with word primes and nonword targets were included in each block. Within blocks, the stimuli were presented in random order.

Procedure. The procedure closely followed that of the previous experiments. The stimuli were presented on an Apple II microcomputer. Each trial began with the presentation of a fixation point for $2.5 \mathrm{sec}$, followed by the prime for $500 \mathrm{msec}$ Targets appeared until subjects made a response (maximum = $2 \mathrm{sec}$ ). The subjects made either vocal or manual responses, as appropriate. The four blocks of stimuli were presented in succession; order of blocks was counterbalanced across subjects.

\section{Results}

The results are summarized in Table 5 . For the lexical decision task, both symmetrical and asymmetrical pairs showed priming effects, compared with unrelated controls in both directions. Analyses of variance were computed based on the subjects' median latencies in each condition. The factors were association (sym-

Table 5

Mean Response Latencies (MRL; in Milliseconds) and Percent Errors (PE), Experiment 3

\begin{tabular}{|c|c|c|c|c|c|c|c|c|}
\hline \multirow[b]{3}{*}{ Condition } & \multicolumn{4}{|c|}{ Symmetrical } & \multicolumn{4}{|c|}{ Asy mmetrical } \\
\hline & \multicolumn{2}{|c|}{ Forward } & \multicolumn{2}{|c|}{ Backward } & \multicolumn{2}{|c|}{ Iiorward } & \multicolumn{2}{|c|}{ Backward } \\
\hline & MRL & PE & MRL & PE & MRL & $\mathrm{PE}$ & MRL & PE \\
\hline \multicolumn{9}{|c|}{ Pronunciation Task } \\
\hline Related & 490 & & 497 & & 483 & & 514 & \\
\hline Unrelated & 498 & & 521 & & 490 & & 507 & \\
\hline Difference & +8 & & +24 & & +7 & & -7 & \\
\hline \multicolumn{9}{|c|}{ Lexical Decision Task } \\
\hline Related & 550 & 0.5 & 528 & 0.3 & 560 & 1.7 & 562 & 1.0 \\
\hline Unrelated & 570 & 2.3 & 573 & 0.0 & 587 & 1.7 & 583 & 1.3 \\
\hline Difference & +20 & & +45 & & +27 & & +21 & \\
\hline
\end{tabular}

Note- There were no crrors on the naming task. metrical, asymmetrical), direction (forward, backward), and type (test vs. control). Significant main effects were obtained for association $[\mathrm{F}(1,29)=42.65, \mathrm{MSe}=489$, $p<.001]$ and type $[F(1,29)=46.28$, MSe 1,319, $\mathrm{p}<.001\}$. There was also a significant association $\mathrm{x}$ type interaction $[F(1.29)=4.24, \mathrm{MSe}=1,028, \mathrm{p}<.05]$. Post hoc tests of simple effects using a pooled error term and Satterthwaitc degrees of freedom indicated that all differences between test and control conditions reached significance at least at the $p<.05$ level. The error data are also given in Table 5 . They indicate that the difference between the forward and backward priming effects for symmetrical associates was due in part to speedaccuracy tradeoffs.

For the pronunciation task, there were main effects of type $[F(1,35)=12.45, \mathrm{MSe}=357, \mathrm{p}<.01]$ and direction $[F(1,35)=73.64, \mathrm{MSe}=361, \mathrm{p}<.001]$. There were significant association $x$ direction $[F(1,35)$ $=7.91, \mathrm{MSe}=182, \mathrm{p}<.01]$ and association $\mathrm{x}$ type $\mathrm{x}$ direction $[F(1,35)=22.10$, MSe $=196, \mathrm{p}<.001]$ interactions. The post hoc tests indicated that differences of $7 \mathrm{msec}$ or greater were significant at the $p<.05$ level. Thus, there was significant facilitation for symmetrical pairs presented in either direction and for asymmetrical pairs in the forward direction. Asymmetrical pairs in the backward direction produced a small amount of inhibition. There were no errors on the naming task.

\section{Discussion}

Results from the lexical decision task replicated Koriat's (1981) finding of a facilitating effect of backward relations between target and prime, under conditions that controlled carefully for forward semantic relations. However, this facilitation did not occur with the pronunciation task. These results are consistent with those of the previous studies. Associative priming occurs via spreading activation, and appears with both response measures. The backward priming effect is not due to this process; rather, it is a postlexical effect resulting from subjects' recognition that the stimuli are related.

Two other aspects of the results should be noted. First, the forward priming effects were much larger in the lexical decision task than in the pronunciation task, as in Experiment 2. This is consistent with the hypothesis that the associative effect in lexical decision derives from two sources, automatic spreading activation and postlexical processing, and suggests that these effects summate. Second, the asymmetrical associates in the backward condition actually yielded a small, but statistically significant, amount of inhibition. One possibility is that the inhibition represents the subjects' recognition that the stimuli were related in a backward direction. In contrast to lexical decision, this postlexical process inhibits, rather than facilitates, performance on the naming task. ${ }^{3}$

The fact that backward prime-target relations produce facilitation through a postlexical process only in 
the lexical decision task has some important implications for recent studies of lexical ambiguity. In these studies (Onifer \& Swinney, 1981; Seidenberg et al., 1982; Simpson, 1981; Swinney, 1979; Tanenhaus et al., 1979), a priming paradigm was used to diagnose the availability of the meanings of ambiguous words. For example, an ambiguous word such as "tire" was presented in context, followed by targets related to altemate meanings ("sleep" and "wheel"). The basic results are that, for ambiguous words with two common meanings, both are initially accessed, with the single contextually appropriate reading subsequently selected very rapidly. This was indicated by the fact that ambiguous words primed targets related to both meanings, regardless of context, immediately after recognition, but only targets related to the contextually appropriate reading shortly thereafter. Koriat's (1981) backward priming effect raised the possibility that multiple access of meaning was a consequence of backward priming from the targets. The present results suggest that, although this interpretation might hold for ambiguity studies that used lexical decision as the response measure (e.g., Onifer \& Swinney, 1981; Swinney, 1979), it would not hold for studies that used the naming task (e.g., Seidenberg et al., 1982; Tanenhaus et al., 1979).

\section{EXPERIMENT 4}

The above experiments have served to distinguish associative priming from other kinds of facilitative effects of contextual information. There is an important question, however, concerning the scope of associative priming. Fischler (1977b) obtained a priming effect for pairs of words that were semantically but not associatively related, using the lexical decision task. This result suggests that activation spreads beyond highly associated entries in the mental lexicon to entries that are merely semantically related. The above results suggested the possibility that semantic priming might also be the result of a postlexical process. This hypothesis was tested in Experiment 4, a replication of the Fischler (1977b) study using both pronunciation and lexical decision tasks.

\section{Method}

Subjects. The subjects were $36(12$ for lexical decision and 24 for naming) McGill University undergraduates who volunteered or were paid to participate.

Stimuli. The stimuli were those used by Fischler (1977b). There were 16 pairs of associated words (e.g., "hurt-pain") and 16 semantically related but nonassociated pairs (e.g., "breadcake"). In the original study, the stimuli were carefully chosen using association norms, and association and semantic-relatedness ratings were obtained. The stimuli in each group were re-paired to form unrelated controls. Thus, each prime and target word appeared twice. Two counterbalanced lists of stimuli containing half the items of each type were prepared. Each stimulus word appeared only once in a list. The stimuli were ordered randomly within lists. In the lexical decision condition, as in Fischler's $(1977 \mathrm{~b})$ original study, there were also 32 pairs of nonwords distributed randomly among the words.
Procedure. The procedure was similar to that used in previous experiments. Stimuli were presented in random order on an Apple II microcomputer. Each subject saw one list. A fixation point appeared for $2.5 \mathrm{sec}$, followed by the prime word for $500 \mathrm{msec}$. The target then appeared until the subject made a response, to a maximum of 2 sec.

\section{Results}

The mean lexical decision and naming latencies are presented in Table 6 . Results for the lexical decision condition replicated those of Fischler (1977b), indicating facilitation for both semantically and associatively related pairs, although the effects $(32$ and $31 \mathrm{msec}$, respectively) were smaller in magnitude than those in Fischler's study. A $2 \times 2$ analysis of variance was computed, with factors of type (semantic or associative) and relatedness (related or unrelated). There was a main effect of type $[F(1,11)=6.91, \mathrm{MSe}=809, \mathrm{p}<.05]$, because latencies for the associative test and control pairs were faster than those for semantic test and control pairs, respectively. There was also a main effect of relatedness $[F(1,11)=16.76, \mathrm{MSe}=688, \mathrm{p}<.002]$ : because related pairs showed facilitation, compared with controls. The interaction was not significant $(F<1)$.

The pronunciation task produced a similar pattern of results, with facilitation occurring for both semantically and associatively related pairs; the effects were small 11 and $9 \mathrm{msec}$, respectively, although statistically reli able. In the analysis of variance, there was a main effec of type $[\mathrm{F}(1,23)=34.87, \mathrm{MSe}=372, \mathrm{p}<.001]$, be cause latencies for associatively related pairs and thei controls were faster than for semantically related pair: and their controls, respectively. There was also a mair effect of relatedness $[\mathrm{F}(1,23)=10.61, \mathrm{MSe}=226$ $\mathrm{p}<.005]$, due to facilitation for related pairs, com pared with controls. The interaction between the twi factors was not significant $(F<1)$.

\section{Discussion}

The results for the associated stimuli replicated thos of Experiments 2 and 3, indicating that associativ

Table 6

Mean Response Latencies (MRL; in Milliseconds) and Percent Errors (PE), Experiment 4

\begin{tabular}{|c|c|c|c|c|c|}
\hline \multirow[b]{3}{*}{ Condition } & \multirow[b]{3}{*}{ Example } & \multicolumn{4}{|c|}{ Task } \\
\hline & & \multicolumn{2}{|c|}{$\begin{array}{c}\text { Lexical } \\
\text { Decision }\end{array}$} & \multicolumn{2}{|c|}{ Pronunciation } \\
\hline & & MRL & $\mathrm{PE}$ & MRL & $\mathrm{PE}$ \\
\hline $\begin{array}{l}\text { Associatively } \\
\text { Related }\end{array}$ & dream-sleep & 536 & 1.0 & 538 & 0.0 \\
\hline $\begin{array}{l}\text { Unrelated } \\
\text { Control } \\
\text { Difference }\end{array}$ & shave-sleep & $\begin{array}{r}567 \\
+31\end{array}$ & 0.5 & $\begin{array}{r}547 \\
+9\end{array}$ & 0.0 \\
\hline $\begin{array}{l}\text { Semantically } \\
\text { Related }\end{array}$ & boy-prince & 557 & 1.6 & 560 & 1.0 \\
\hline $\begin{array}{l}\text { Unrelated } \\
\text { Control }\end{array}$ & fog-prince & 589 & 2.1 & 571 & 0.8 \\
\hline Difference & & +32 & & +11 & \\
\hline
\end{tabular}


priming occurs with both tasks. Semantic priming resembled associative priming, and contrasted with syntactic and backward priming, in that it also occurred with both tasks. As in previous experiments, facilitation was larger in lexical decision than in pronunciation. The results suggest that spreading activation contributes to both associative and semantic priming, with the greater facilitation effect in lexical decision due to the additional contribution of postlexical processing. The results support Fischler's (1977b) conclusion that lexical priming due to spreading activation can occur when word pairs are related in meaning but are not associated.

The magnitude of the associative priming effect was smaller than that obtained in Experiments 2 and 3. The stimuli in Experiment 4 were taken from Fischler (1977b); although the associated pairs were higher in association value than the semantically related pairs, they were not as highly associated as in the above experiments. Fischler's stimuli typically were moderately associated pairs, such as "hurt-pain," whereas those in Experiments 2-3 here were very high associates, such as "doctor-nurse." Thus, the magnitude of the associative effect is a function of the degree of association.

The magnitude of the semantic priming effect was also quite small, but it is not clear whether the effect could have been increased substantially by selecting word pairs that were more semantically related (yet unassociated). Whereas Warren (1977) reported priming effects of similar magnitude (ranging from 5 to $14 \mathrm{msec}$ ), Huttenlocher and Kubicek (1983) failed to obtain a semantic priming effect using the narning task; their stimuli were the names of related objects (e.g., "drumguitar"). They also failed to obtain a stimulus proportion $\mathrm{x}$ relatedness interaction (as in Experiment 2). It appears that the semantic priming effect is small and involves a limited pool of related words. There is an additional problem in estimating the scope of semantic priming in that associative relatedness can be defined and identified more clearly than can semantic relatedness. Stimuli can be semantically related along several dimensions (synonymy, antonomy, category membership, etc.). As the Warren (1977) study indicated, the time course of semantic priming differs depending on the type of semantic relation. Lack of a clear understanding of which dimensions of semantic relatedness produce facilitation may account for the small and inconsistent effects obtained. Nonetheless, it is clear that some such effects can be obtained with the naming task (see de Groot, 1983, for discussion of the scope of spreading activation). ${ }^{4}$

\section{GENERAL DISCUSSION}

The results of these studies emphasize the importance of considering the loci of contextual effects on word recognition. Whereas associative and semantic priming influenced immediate decoding, the syntactic, backward, and proportionality effects resulted from postlexical processing. The latter effects may reflect an important fact about language processing, namely, that readers and listeners are able to integrate rapidly the lexical information accessed in recognition with the information provided by a context. However, the effects do not show that the decoding of a word changes as a function of context, and thus do not violate the autonomy hypothesis. The associative and semantic priming effects are also consistent with this hypothesis, because they are internal to the lexicon.

Consistent with an interactive model, however, it could be argued that all of the contexts in the above studies facilitated identification of the targets themselves. Recent models of word recognition construe the process as involving the discrimination of the input from a cohort of alternatives (Marslen-Wilson \& Tyler, 1980; Rumelhart, 1977). Contextual constraints operate in these models either by limiting the composition of the cohort or by facilitating the elimination of members of the cohort. In Marslen-Wilson and Tyler's model, for example, syntactic constraints of the sort studied in Experiment 1 function in the latter way. The problem with this interpretation is that it provides no basis for the task difference. If contextual information functioned in this way to facilitate recognition of the target, it should also have facilitated retrieval of its pronunciation.

\section{Basis of the Task Differences}

The results show that, under the conditions of these experiments, as in the Stanovich and West (1983; West \& Stanovich, 1982) studies, lexical decisions were influenced by postrecognition judgments of primetarget relations more than naming responses. An explanation of the different pattern of results follows from an understanding of the requirements of each task. Lexical decision is a signal detection task for which performance depends upon the discriminability of words and nonwords and the subjects' response criteria, both of which may vary across experiments and individuals. The naming task differs in at least two respects. First, subjects do not have to discriminate between words and nonwords; second, subjects' responses are constrained by the requirement that the subjects pronounce stimuli correctly. This ensures that each word must be processed to the point at which its pronunciation is known.

On the view that lexical decision is a signal detection task, contextual information could influence either the subject's sensitivity or bias. The results are consistent with the view that only semantic-associative priming due to spreading activation changes sensitivity; the other contextual effects result from postlexical processes that influence bias. The latter are more relevant to the lexical decision task because of the task-specific requirement that subjects discriminate between words and nonwords.

Postlexical processes could bias lexical decisions in several ways. First, context words could lead subjects to expect a word or nonword target on particular trials. 
In most priming studies (including the above), there are more word-word trials than word-nonword trials. Hence, word primes could induce subjects to expect word targets. This suggests that it should be possible to vary the differences between word and nonword conditions (in terms of latencies and errors) by changing these contingencies. However, this factor would not account for the observed differences among various word-word conditions (e.g., associated vs. unrelated pairs). This type of bias should operate even when none of the wordword pairs are related.

The congruence of prime-target pairs along a particular dimension (e.g., semantic, associative, syntactic) could also bias subject responses. In most (although not all) lexical decision experiments, the word and nonword stimuli are chosen so as to be difficult to discriminate. The stimuli consist of orthographically legal, pronounceable letter strings, some of which happen to be words. The stimuli are selected so as to eliminate other structural differences between words and nonwords. Contextual information provided by the primes might previde an additional basis for making the difficult discrimination between the two types of letter strings, because it provides information concerning the likelihood of a word or nonword target. The decision rules that subjects employ may be quite complex and may vary depending upon the composition of the stimuli. For example, whenever the prime-target pair is congruent (e.g., semantically related), the target must be a word. Thus, a subject might judge the congruence of the pair in order to facilitate the lexical decision to the target. The semantic-matching strategy described by Neely (1977) operated in this way. Given that the target is a nonword, the prime-target pair must be incongruent; therefore, subjects might be biased to respond "nonword" whenever the stimuli are incongruent. Both strategies will fail if the target is a word but incongruent with the context. These strategies would yield the "inhibition-dominant" pattern obtained in many context studies (Stanovich \& West, 1979, 1983; West \& Stanovich, 1982). Use of these heuristics could be expected to depend on the nature of the stimuli. Subjects would be likely to use them if the proportion of incongruent word-word pairs was small compared with the proportion of congnuent word-word and word-nonword pairs, as is typical of most context studies.

This account applies to the results of Experiment 2 in a straightforward way. Increasing the proportion of associatively related pairs leads the subject to expect that a word prime will be followed by a related word target. The larger priming effect with a greater proportion of related trials results from the positive confirmation of this expectancy on a greater proportion of trials, and from greater inhibition on trials when the expectation is disconfirmed. Although the proportion of related trials was manipulated between subjects in Experiment 2, the results are consistent with this view. The increase in the magnitude of the priming effect resulted both from faster latencies on the related trials and slower latencies on the unrelated trials. A similar account applies to the syntactic priming effect in Experiment 1 . The subject learns that if a prime-target pair is syntactically congruent, the target must be a word. If the pair is incongruent, the target is likely to be a nonword. The strategy fails when the target is both a word and syntactically incongruent, yielding inhibition.

If this view is correct, however, the inhibitiondominant pattern typical of context studies is not a necessary outcome; a different pattern of results would be obtained if the composition of the stimuli did not favor the use of these strategies. For example, if the proportion of (incongruent) word-nonword pairs were high, the inhibition to incongruent word-word pairs might decrease. In general, if the relatedness of context and target influence the subject's bias toward a word or nonword response, it should be possible to manipulate these biases to produce widely varying patterns of results. Generalizations about context effects in lexical decision must take into account this potential for varying response strategies.

It is also possible, however, that the contextual effects in the lexical decision task are due at least in part to processes that are not under strategic control. As West and Stanovich (1982) noted, lexical decisions to words in context produce a Stroop-like effect. Although subjects could, in principle, base the decision solely on the results of processing the targets, they use information concerning the congruence of prime and target anyway. The extent to which subjects can control the use of congruency judgments in making lexical decisions is unclear. If context effects in lexical decision are genuinely Stroop-like, they should occur regardless of subject strategies based on the proportions of stimuli from various conditions. Several factors suggest that this account may be correct, at least for some types of congruency relations. Another distinguishing charac. teristic of the lexical decision task is that it requires the subject to consciously label a target as a word or $a$ nonword. Subjects may conflate this decision with the judgment that the prime-target pair is congruent of incongruent, just as in the Stroop task they conflate the name of the word with the name of the color it is printed in. It may be difficult to inhibit recognizing a least some relations between word and context, because identifying them is a normal and overlearned part of the comprehension process. The extent to which this is trut may depend on the type of congruency relation. Somt relations, such as syntactic congruence, normally are recognized in the comprehension process. Others, suck as backward associative relations between stimuli, may be peculiar to the conditions of a lexical decision experi ment. Thus, although all of the contextual effects in the above lexical decision experiments resulted from post lexical processing, it may be possible to eliminate som! effects by varying the stimuli; others would not br eliminable because they result from automatic compre 
hension processes that yield information that then interferes with the target dicision. This is an interesting question for future research. ${ }^{5}$

The naming task typically does not show postlexical effects because it does not involve discriminating word and nonword stimuli. The subject's task is to say each word correctly; no expectations concerning the relatedness of stimuli along a particular dimension can assist in identifying particular targets (Forster, 1979). In essence, there are no postlexical context effects because there is no decision to bias. Associative semantic priming due to spreading activation occurs in both tasks because it influences sensitivity to the target, rather than bias to a word or nonword decision.

Several other observations about the task differences should be noted. First, the naming task differed from lexical decision in the above experiments in that there were nonword stimuli only in the latter. However, it is the requirement that subjects discriminate between word and nonword stimuli in the lexical decision task that is crucial, not the mere presence of nonwords. Second, the fact that syntactic relations between primetarget pairs, and changes in the proportion of related pairs, did not affect naming might be taken to indicate that this information simply was not recognized in this task because it could not facilitate naming. This implies that access of this information results from a strategy for performing the lexical decision task. However, it is possible that these relations between stimuli were recognized, as in lexical decision, but simply had no effect on the naming response. The data are ambiguous in this regard. If it is true that subjects cannot inhibit recognition of some prime-target relations, it could nonetheless be the case that this information has no effect on naming. Thus, the data show that when subjects recognize certain prime-target relations, this information can bias lexical decisions, but has little influence on naming. Whether such relations are detected solely as part of a strategy for performing the decision task or as an automatic consequence of the comprehension process is unclear. The naming data are compatible with both alternatives; no effects of prime-target relations would result either if (1) this information were not accessed or if (2) the information were accessed, but had no effect on the naming response.

Third, it may be possible to create conditions under which relations between primes and targets that are detected postlexically do influence naming. Although these conditions are not represented in most lexical priming or sentence-context studies, this is not to say they could never occur. The backward relations between stimuli in Experiment 3 actually yielded a small but significant amount of inhibition, suggesting that subjects had detected that the stimuli were related and that this interfered with the naming response. It may be possible to construct other conditions under which this occurs. The basic difference between the tasks, then, is not that lexical decisions are influenced by postlexical process- ing, whereas naming is not. Rather, because of the signal detection character of the task, lexical decisions are much more likely to be influenced by such processes; there may be Stroop-like interference effects that are very difficult to eliminate. Postlexical processing is unlikely to influence naming because it cannot facilitate the response and because the subject does not have to make a conscious word/nonword decision. Under the conditions represented by most lexical priming and sentence-context studies, there are much greater postlexical effects in the lexical decision task. Nonetheless, it may be possible to create conditions under which prime-target relations are recognized and influence the naming response; as in Experiment 3, however, this leads to interference rather than to facilitation.

Finally, these differences between the tasks are also relevant to studies of single-word recognition. The lexical decision and naming tasks have been used to evaluate the effects of various structural characteristics of words (such as orthographic or phonological regularity) on recognition. These effects in lexical decision vary greatly, depending upon experiment-specific factors. For example, Shulman, Hornak, and Sanders (1978) showed that properties of the nonwords influenced whether subjects accessed phonological information in reading words. Waters and Seidenberg (1983) showed that effects of spelling-sound irregularity in lexical decision depend upon the composition of the stimuli; however, naming performance is not conditional in this manner. The differing lexical decision results follow from the fact that performance depends on the discriminability of words and nonwords and on subject biases influenced by the proportion of items from different conditions. The variability in lexical decision performance suggests that although lexical decision latencies are typically longer than naming latencies (Forster \& Chambers, 1973; Frederiksen \& Kroll, 1976), this is not a necessary outcome. This finding may merely reflect the conditions that are typical of word-recognition experiments. Under other conditions, lexical decision latencies can in fact be faster than naming latencies (Seidenberg, Waters, Barnes, \& Tanenhaus, in press). ${ }^{6}$

\section{Implications for Normal Reading}

The primary interest of the above results and discussion lies in the theoretical analyses of the possible loci of contextual effects, and how the tasks are performed. It is also important to consider how this research relates to the comprehension process as it occurs under more natural conditions. Although reliable semantic and associative priming effects can be observed under appropriate conditions, this process probably does not assume an important role in comprehension. The effects are very small, and seem to depend on the close contiguity of highly related words. Semantic and associative priming effects provide useful information about the organization of the mental lexicon and evidence for automatic processes that are not under conscious con- 
trol. However, their importance to the comprehension of normal text should not be overstated.

Regarding the postlexical effects, it is important to understand the processes by which readers and listeners integrate words and contexts. Data from context studies using the lexical decision task may be informative in this regard. However, as the task is currently used, it is not possible to distinguish between integrative processes that are a natural part of the comprehension process and those that occur solely for the purpose of performing the lexical decision task. Although studying the effects of changes in the proportion of related trials, or backward relations between stimuli, may be helpful in identifying the possible loci of contextual effects and in understanding how the lexical decision task is performed, these effects probably have little relevance to normal reading.

These observations suggest that the lexical decision task should be used with extreme caution. The task has been used widely to study both the structural properties of words that influence recognition and the influence of contextual information on recognition. In both cases, however, task-specific factors can lead to highly variable results. There seem to be two alternatives. One is to use a signal detection methodology, explicitly manipulating the stimuli and separately evaluating sensitivity and bias. Hale and Johnston (1983) provided an example of this approach. They also concluded that contextual information influences bias rather than sensitivity. The other alternative is to develop tasks that introduce fewer extraneous factors, permitting a much more direct analysis of the normal reading process. It is clear, however, that simple inferences from performance on the lexical decision task to the normal comprehension process may not be valid.

\section{Conclusions}

The results indicate that there are two possible loci for contextual effects on word recognition. First, there are prelexical effects due to semantic or associative priming. This research preserves the idea that associative and semantic priming occurs as an automatic consequence of spreading activation. The process is strictly limited, however, to highly associated or semantically related words, and to the forward direction. Second, there are postlexical effects, due to subject judgments of the relatedness of word and context. Because of the signal detection character of the task, lexical decisions are likely to be influenced by such processes. In future research, it would be useful to concentrate on postlexical processes that occur as a normal part of comprehension, rather than as steps in performing a lexical decision.

A general implication of these studies is that, in an evaluation of the role of contextual information in word recognition, it is necessary to be specific about the loci of any observed effects. The above studies are not inconsistent with the general notion of interactions among different sources of information in language comprehension. Rather, they demonstrate that nonlexical knowledge does not affect the operations of the lexical module (Forster, 1979; Seidenberg \& Tanenhaus, in press; Tanenhaus et al., 1984). Different types of information are undoubtedly used in constructing an interpretation of a sentence. However, they may become available as the output of autonomously functioning, modular subsystems. Modules do not have access to the internal operations of other modules, but they interact upon output (Fodor, 1983; Tanenhaus et al., 1984).

It should also be noted that there are important interactive processes within the lexicon. The McClelland and Rumelhart (1981) model, for example, is largely concerned with interactions of this kind. Word recognition depends on knowledge of the relations that hold among lexical items in memory (e.g., orthographic, semantic, or phonological); this information represents the virtual context of occurrence, and may be more central to the recognition process than interactions with the literal context.

\section{REFERENCES}

Becker, C. A., \& Killion, T. H. (1977). Interaction of visual and cognitive effects in visual word recognition. Journal of Experimental Psychology: Human Perception and Performance, 5, 252-259.

Cainns, H. S., Cowaht, W., \& Jablon, A. D. (1981). Effect of prior context upon the integration of lexical information during sentence processing. Journal of Verbal Learning and Verbal Behavior, 10, 445-453.

Collins, A. M., \& Loftus, E. F. (1975). A spreading-activation theory of semantic processing. Psychological Review, 82, 407-428.

Davelank, E., Coltheart, M., Begner, D., \& Jonasgon, J. T. (1978). Phonological recoding and lexical access. Memory \& Cognition, 6, 391-402.

DE Groot, A. M. B. (1983). The range of automatic spreading activation in word priming. Journal of Verbal Learning and Verbal Behavior, 22, 417-436.

den Heyer, K., Briand, K., \& Dannenbring, G. L. (1983). Strategic factors in a lexical decision task: Evidence for automatic and attention-driven processes. Memory Cognition, 11, 374-381.

Frschlen, I. (1977a). Associative facilitation without expectancy in a lexical decision task. Journal of Experimental Psychology: Human Perception and Performance, 3, 18-26.

Fischlen, I. (1977b). Semantic facilitation without association in a lexical decision task. Memory \& Cognition, 5, 335-339.

Fodor, J. A. (1983). Modularity of mind. Cambridge, MA: Bradford-MIT Press.

Fonster, K. I. (1979). Levels of processing and the structure of the language processor. In W. E. Cooper \& E. C. T. Walker (Eds.), Sentence processing: Psycholinguistic studies presented to Merrill Garrett. Cambridge, MA: MIT Press.

Fonster, K. I., \& Chambens, S. M. (1973). Lexical access and naming time. Journal of Verbal Learning and Verbal Behavior, 12, 627-635.

Frederiksen, J. R., \& Kroll, J. F. (1976). Spelling and sound: Approaches to the internal lexicon. Journal of Experimental Psychology: Human Perception and Performance, 2, 361-379.

Goodman, G. O., McClelland, J. L., \& GibBs, R. W., JR. (1981). The role of syntactic context in word recognition. Memory \& Cognition, 9, 580-586. 
Gough, P., Alford, J. A., \& Holley-Wilcox, P. (1981) Words and context. In O. J. L. Tzeng \& H. Singer (Eds.), Perception of print. Hillsdale, $\mathrm{NJ}$ : Erlbaum.

Hale, B. L., \& Johnston, J. C. (1983, November). How sentence context affects word identification: A signal detection theory analysis. Paper presented at the meeting of the Psychonomic Society, San Diego.

HUTtENLOChER, J., \& KUBiceK, L. F. (1983). The source of relatedness effects on naming latency. Journal of Experimental Psychology: Learning, Memory, and Cognition, 9, 486-495.

Kiger, J. I., \& Glass, A. L. (1983). The facilitation of lexical decisions by a prime occurring after the target. Memory \& Cognition, 11, 356-365.

Koniat, A. (1981). Semantic facilitation in lexical decisions as a function of prime-target association. Memory \& Cognition. 9, 587-598.

Lukatela, G., Kostic, A., Feldman, L. B., \& Turvey, M. T. (1983). Grammatical priming of inflected nouns. Memory \& Cognition, 11, 59-63.

Lukatela, G., Moraca, J., Stojnov, D., Savic, M. D., Katz, L., \& Turvey, M. T. (1983). Grammatical priming effects between pronouns and inflected verb forms. Status report on speech research, SR-73, 27-42. New Haven, CT: Haskins Laboratories.

Marslen-Wilson, W. D., \& Tyler, L. K. (1980). The temporal structure of spoken language comprehension. Cognition, 8 , $1-71$.

MoClelland, J. L., \& Rumelhart, D. E. (1981). An interactive activation model of context effects in letter perception: Part 1. An account of basic findings. Psychological Review, 88, 375-407.

Merrill, E., Sperber, R. D., \& McCauley, C. (1981). Differences in semantic coding as a function of reading comprehension skill. Memary \& Cognition, 9, 618-624.

Meyer, D. M., \& Schvaneveldt, R. W. (1971). Facilitation in recognizing pairs of words: Evidence of a dependence between retrieval operations. Journal of Experimental Psychology, 90, 227-234.

Meyer, D. M., Schvaneveldt, R. W., \& Ruddy, M. G. (1975). Loci of contextual effects on visual word recognition. In P. M. A. Rabbitt \& S. Dornic (Eds.), Attention and performance $V$. New York: Academic Press.

NeELY, J. H. (1977). Semantic priming and retrieval from lexical memory: Roles of inhibitionless spreading activation and limited-capacity attention. Journal of Experimental Psychology: General, 106, 226-254.

Onifer, W., \& SWInney, D. A. (1981). Accessing lexical ambiguities during sentence comprehension: Effects of frequency of meaning and contextual bias. Memory \& Cognition, 9, 225-236.

Posnen, M. I., \& Snyder, C. R. (1975). Attention and cognitive control. In R. L. Solso (Ed.), Information Processing and Cognition: The Loyola Symposium. Hillsdale, NJ: Erlbaum.

RUMELHART, D. E. (1977). Toward an interactive model of reading. In S. Dornic (Ed.), Attention and performance VI. Hillsdale, NJ: Erlbaum.

Schuberth, R. E., Eimas, P. D. (1977). Effects of context on the classification of words and nonwords. Journal of Experimental Psychology: Human Perception and Performance, 3, 27-36.

Seidenberg, M. S., \& Tanenhaus, M. K. (in press). Modularity and lexical access. In I. Gopnik (Ed.), McGill Studies in the Cognitive Sciences. Norwood, NJ: Ablex.

Seidenbero, M. S., Tanenhaus, M. K., Leiman, J. L., \& Bienrowski, M. (1982). Automatic access of the meanings of ambiguous words in context: Some limitations of knowledgebased processing. Cognitive Psychology, 14, 489-537.

Seidenbero, M. S., Waters, G. S., Barnes, M. A., \& Tanenhaus, M. K. (in press). When does irregular spelling or pronunciation influence word recognition? Journal of Verbal Learning and Verbal Behavior.

Shiffrin, R. M., \& Schneiden, W. (1977). Controlled and automatic human information processing II. Perceptual learning, automatic attending and a general theory. Psychological Review, 84, 127-190.

Shulman, H. G., Hornak, R., \& Sanders, E. (1978). The effects of graphemic, phonemic, and semantic relationships on access to lexical structure. Memory Cognition, 6, 115-123.

Simpson, G. B. (1981). Meaning, dominance and semantic context in the processing of lexical ambiguity. Journal of Verbal Learning and Verbal Behavior, 20, 120-136.

Stanovich, K. E. (1980). Toward an interactive-compensatory model of individual differences in the development of reading fluency. Reading Research Quarterly, 16, 32-71.

Stanovich, K. E., \& WEST, R. F. (1979). Mechanisms of sentence context effects in reading: Automatic activation and conscious attention. Memory \& Cognition, 7, 77-85.

Stanovich, K. E., \& West, R. F. (1981). The effect of sentence context on ongoing word recognition: Tests of a two-process theory. Journal of Experimental Psychology: Human Perception and Performance, 7, 658-672.

Stanovich, K., \& West, R. F. (1983). On priming by a sentence context. Journal of Experimental Psychology: General, 112, 1-36.

SwinkEy, D. A. (1979). Lexical access during sentence comprehension: (Re)consideration of context effects. Journal of Verbal Learning and Verbal Behavior, 18, 645-660.

Tanenhaus, M. K., Carlson, G. N., \& Seidenberg, M. S. (1984). Do listeners compute linguistic representations? In A. Zwicky, L. Kartunnen, \& D. Dowty (Eds.), Natural language parsing: Psycholingulstic, theoretical, and computational perspectives. Cambridge: Cambridge University Press.

Tanenhaus, M. K., Leiman, J. L., \& Seidenerg, M. S. (1979). Evidence for multiple stages in the processing of ambiguous words in syntactic contexts. Journal of Verbal Learning and Verbal Behavior, 18, 427-441.

The108, J., \& Muise, J. G. (1977). The word identification process in reading. In N. J. Castellan, D. B. Pisoni, \& G. R. Potts (Eds.), Cognitive theory (Vol. 2). Hillsdale, NJ: Erlbaum.

Tweedy, J. R., Lapinski, R. H., \& Schvaneveldt, R. W. (1977). Semantic-context effects on word recognition: Influence of varying the proportion of items presented in an appropriate context. Memory d Cognition, 5, 84-89.

WARREN, R. E. (1972). Stimulus encoding and memory. Journal of Experimental Psychology, 94, 90-100.

WArren, R. E. (1977). Time and the spread of activation in memory. Journal of Experimental Psychology: Human Learning and Memory, 3, 458-466.

W Aters, G. S., \& SeIDEnberg, M. S. (1983, May). Spelling sound effects in reading: Time course and decision criteria. Paper presented at the meeting of the Canadian Psychological Association.

Wegt, R. F., \& Stanovich, K. E. (1982). Source of inhibition in experiments on the effect of sentence context on word recognition. Journal of Experimental Psychology: Learning, Memory, and Cognition, 8, 385-399.

\section{NOTES}

1. The term "backward priming" has been used in two slightly different senses. In Koriat's (1981) study, it referred to the effect of a backward association between words (e.g., "fruitapple") on a lexical decision to a target presented after a prime. Kiget and Glass (1983) also used stimuli such as "fruit-apple," but required a lexical decision to a target that preceded a prime. They also obtained facilitation and termed it "backward priming." In this paper, "prime" will refer to the word presented first, and "target" to the word presented second. "Backward priming" will then refer to facilitation in recognizing a target due to a relationship from the target to the prime. 
2. These ratings could only supplement our intuitions in constructing the stimuli, because they were based on conscious relatedness judgments. As we argue, such postlexical judgments are influenced by factors such as backward relations between stimuli. The ratings were very similar for symmetrical associates presented in both directions, whereas asymmetrical associates were rated as more related in the forward direction than in the backward direction. Nonetheless, the backward asymmetrical pairs were rated as more related than were the controls. We attribute this to the kind of postlexical judgment the experiment was designed to evaluate.

3. There was a greater facilitation for symmetrical associates presented backward than for those presented forward, but this difference is probably unimportant because stimuli were arbitrarily assigned to "forward" and "backward" conditions. The difference is also due in part to speed-accuracy tradeoffs. The subjects often noticed the backward relations between words, even in the naming task, and remarked upon their oddity.

4. Using pictures corresponding to semantically related words, Huttenlocher and Kubicek (1983) did obtain a priming effect; the magnitude of this effect varied as a function of the proportion of related stimuli. They concluded that presentation of a picture facilitates the identification of a subsequent picture (i.e., visual processing and categorization). This is analogous to a prelexical priming effect in word recognition. However, their effect might have been due to processes following the recognition of prime and target pictures (analogous to the postlexical processes observed above). Several aspects of their data are suggestive of the latter interpretation. First, the interaction of relatedness and proportion is suggestive of a postlexical effect, as in Experiment 2. Second, picture-naming latencies were 52\%-63\% slower than word-naming latencies, which might allow for more intervention of controlled processes. Third, the facilitation in naming related pictures, and the increase in this effect with the proportion of related stimuli, were due to very long latencies on unrelated trials, rather than to facilitation on related trials, also consistent with a postlexical locus. Finally, although Huttenlocher and Kubicek obtained a frequency effect in picture naming, it did not interact with relatedness or proportion of related stimuli. They concluded that frequency and relatedness influence different aspects of picture namingfrequency, the retrieval of the name, and relatedness, the categorization or identification of the object. An alternative interpretation, however, is that whereas frequency influences retrieval of the name, relatedness influences a postrecognition judgment, rather than perceptual processing. Thus, the locus of facilitating effects in picture priming is not clear.

5. It appears that all of the postlexical effects studied in the above experiments could be eliminated by varying the conditions in simple ways. Goodman et al. (1981) eliminated the syntactic priming effect by intermixing syntactically related stimuli with semantically related pairs. Expectations based on the proportion of related stimuli could be eliminated by reducing the proportion of related trials (as in Fischler, 1977a). Backward relations between stimuli might not be recognized in a study in which the proportion of such trials is small. More interesting is whether the congruence effects in sentence-context studies such as Stanovich and West's (1983) could be eliminated A related question is whether contextual facilitation of nonword decisions (e.g., Neely, 1977; Schuberth \& Eimas, 1977) occurs as a by-product of the lexical decision strategy or because subjects cannot inhibit congruence judgments.

6. Seen in this light, it is clear that one of the assumptions that motivated using the lexical decision task as a tool in reading research will not necessarily hold. The attraction of the task was that it seemed to require subjects to recognize each word (Davelaar, Coltheart, Besner, \& Jonasson, 1978). However, this is not necessarily true. Consider a case in which the signal and noise distributions are maximally distinct (e.g., the word stimuli are all orthographically legal, and the nonword stimuli are orthographically illegal); the task might then be performed with very superficial processing of individual stimuli. Naming often has been compared unfavorably with lexical decision, because it was thought that the task could be performed nonlexically, that is, on the basis of abstract knowledge of spelling-sound correspondences (Davelaar et al., 1978). However, the many irregularities in the pronunciations of English words and the requirement that the words be named correctly mean that subjects must recognize words in order to be certain of their pronunciations. Thus, words are not necessarily processed more deeply with the lexical decision task.

\begin{tabular}{ll}
\multicolumn{1}{c}{ Stimuli From Experiment 3 } \\
\hline \multicolumn{1}{c}{ Symmetrical Associates } \\
\hline $\begin{array}{l}\text { city-town } \\
\text { bread-butter } \\
\text { king-queen }\end{array}$ & $\begin{array}{l}\text { bath-tub } \\
\text { sun-moon } \\
\text { mouse-cat }\end{array}$ \\
$\begin{array}{ll}\text { car-truck } \\
\text { jump-skip }\end{array}$ & soep-shallow \\
then-now & shoot-gun \\
thread-needle & sheep-wool \\
priest-church & spider-web \\
live-die & sleep-dream \\
\multicolumn{1}{c}{ Asymmetrical Associates } \\
\hline green-grass \\
fruit-fly & find-lose \\
crack-down & bell-hop \\
high-way & crew-cut \\
bus-boy & soft-core \\
hatch-back & lip-stick \\
bed-pan & fire-truck \\
foot-note & stage-hand \\
eye-ball & crow-bar \\
head-line & book-worm \\
space-ship & coat-rack \\
\hline
\end{tabular}

Note-Stimuli are listed in "forward" direction.

(Manuscript received September 10, 1983; revision accepted for publication February 27, 1984.) 